\title{
The Improvement of Civic Education Instructional Quality Throught Make a Match Model Assisted Picture Card Media
}

\author{
Leny Shela Purnianingrum \\ SDIT Al-Hikmah Mayong \\ leny090393@gmail.com
}

\section{Article History}

received 3/12/2020

\begin{abstract}
Purpose of research to improve the quality of Civic Education Instructional Quality Throught Make a Match Model Assisted Picture Card Media. Research design used classroom action research, it conducted of three cycles with four stages: planning, running, observing, and reflecting. The techniques data collection used observation, test, documentation, interview and field notes. The techniques of data analized used Qualitative and quantitative descriptive. The research findings showed: (1) the skill of teacher improved in every cycle. In cycle l, the score was 28 with good criteria. In cycle II, the score was 32 with good criteria. In cycle III, the score was 35 with very good criteria, (2) Students activity showed improvement in every cycle. In cycle I, the score was 21,7 with enough criteria In cycle II, the score was 25,13 with good criteria. In cycle III, the score was 28,21 with good criteria, (3) Students learning outcome showed improvement in every cycle with classical comprehension in cycle I 63\%, cycle II 76,32\%, and cycle III 86,84\%. Conclusion of the research is make a match Model Assisted Picture Card Media can improve the quality of civic education instructional.
\end{abstract}

Keywords: quality, intructional, civic education, make a match, picture card media

\begin{abstract}
Abstrak
Penelitian ini bertujuan untuk meningkatkan kualitas pembelajaran PKn melalui model make a match berbantuan media kartu bergambar siswa kelas V SDN Karanganyar 02 Kota Semarang. Desain penelitian menggunakan penelitian Tindakan kelas dilaksanakan dalam 3 siklus dengan empat tahapan, yaitu perencanaan, pelaksanaan, observasi, dan refleksi. Teknik pengumpulan data menggunakan observasi, tes, dokumentasi, wawancara dan catatan lapangan. Analisis data menggunakan deskriptif kualitatif dan deskriptif kuantitatif. Hasil penelitian menunjukkan: 1) keterampilan guru pada siklus I memperoleh skor 28 dengan kriteria baik, siklus II memperoleh skor 32 dengan kriteria baik dan siklus III memperoleh skor 35 dengan kriteria sangat baik, 2) aktivitas siswa siklus I memperoleh rata-rata skor 21,7 dengan kriteria cukup, siklus II memperoleh rata-rata skor 25,13 dengan kriteria baik dan siklus III memperoleh rata-rata skor 28,21 dengan kriteria baik, 3) hasil belajar siswa dengan ketuntasan klasikal siklus I 63\%, siklus II $76,32 \%$ dan siklus III $86,84 \%$. Simpulan penelitian ini membuktikan model make a match berbantuan media kartu bergambar dapat meningkatkan kualitas pembelajaran PKn.
\end{abstract}

Kata kunci: kualitas, pembelajaran, PKn, make a match, media kartu bergambar

Social, Humanities, and Education Studies (SHEs): Conference Series https://jurnal.uns.ac.id/shes 


\section{PENDAHULUAN}

Peraturan Menteri Pendidikan Nasional Republik Indonesia Nomor 22 Tahun 2006 tentang standar isi untuk satuan pendidikan dasar dan menengah bahwa Pendidikan Kewarganegaraan merupakan mata pelajaran yang memfokuskan pada pembentukan warga negara yang memahami dan mampu melaksanakan hak-hak dan kewajibannya untuk menjadi warga negara Indonesia yang cerdas, terampil dan berkarakter yang diamanatkan oleh Pancasila dan UUD 1945. Pendidikan di Indonesia diharapkan dapat mempersiapkan peserta didik menjadi warga negara yang memiliki komitmen kuat dan konsistensi untuk mempertahankan Negara Kesatuan Republik Indonesia (BNSP, 2006: 271).

Tujuan pembelajaran Pendidikan Kewarganegaraan dalam Kurikulum Tingkat Satuan Pendidikan membentuk peserta didik memiliki kemampuan sebagai berikut: a) Memahami konsep Pendidikan Kewarganegaraan. b) Berpartisipasi secara aktif dan bertanggung jawab. c) Bertindak secara cerdas dalam kegiatan bermasyarakat, berbangsa, bernegara, serta anti korupsi. d) Berkembang secara positif dan demokratis untuk membentuk diri berdasarkan karakterkarakter masyarakat Indonesia agar dapat hidup bersama dengan bangsa lain. e) Berinteraksi dengan bangsa-bangsa lain dalam peraturan dunia secara langsung dan tidak langsung dengan memanfaatkan teknologi dan informasi (BNSP, 2006: 271).

Berdasarkan hasil observasi pembelajaran PKn di SDN Karanganyar 02 Kota Semarang terdapat beberapa kekurangan, diantaranya guru kurang melakukan variasi dalam pembelajaran, guru kurang memanfaatkan media untuk menunjang pembelajaran serta guru kurang memperhatikan siswa yang berbicara sendiri di kelas. Sementara dari siswanya sendiri menjadi kurang antusias, kurang tertarik dalam mengikuti pembelajaran dan cenderung pasif serta siswa lebih memilih berbicara sendiri. Hal ini menyebabkan materi yang diberikan oleh guru kurang dapat diterima siswa dengan baik, sehingga berdampak pada hasil belajar yang kurang optimal.

Hal tersebut berdampak terhadap hasil belajar siswa pada pembelajaran PKn. Data hasil belajar siswa kelas V SDN Karanganyar 02 menunjukkan banyak siswa yang belum mencapai Kriteria Ketuntasan Minimal (KKM) yang ditetapkan sekolah yaitu 66. Terlihat dari 42 siswa yang ada di kelas, hanya 11 siswa (26\%) yang tuntas, sedangkan 31 siswa lainnya (74\%) nilainya masih di bawah KKM.

Untuk memecahkan masalah pembelajaran tersebut, maka dilakukan penelitian tindakan kelas melalui model Make a Match berbantuan media kartu bergambar. Sehingga rumusan masalah dalam penelitian ini adalah: Bagaimanakah meningkatkan kualitas pembelajaran PKn melalui model make a match berbantuan media kartu bergambar siswa kelas V SDN Karanganyar 02 Kota Semarang?

Penelitian ini menggunakan pembelajaran kooperatif tipe Make a Match. Model Make a Match diperkenalkan oleh Curran (dalam Eliya 2009). Make a match atau mencari pasangan merupakan salah satu model kooperatif yang bisa mengembangkan kemampuan siswa. Model ini sangat disenangi oleh siswa karena tidak menjemukkan, guru memancing kreativitas siswa menggunakan media (Sofan Amri dan lif Khairu, 2010: 182 dalam Muslimah, 2012).

Kelebihan dari model make a match adalah: (1) Dapat meningkatkan aktivitas belajar siswa, baik secara kognitif maupun fisik. (2) Karena ada unsur permainan, maka model make a match lebih menyenangkan. (3) Meningkatkan pemahaman siswa terhadap materi yang dipelajari dan meningkatkan motivasi belajar siswa. (4) Efektif sebagai sarana melatih keberanian siswa untuk tampil presentasi. (5) Efektif melatih kedisiplinan siswa menghargai waktu untuk belajar. (Huda, 2014: 253-254). 
Menurut Surachman (1996: 28 dalam Suharti, 2009) menyatakan bahwa media kartu bergambar mampu meningkatkan perhatian, minat, meningkatkan daya kreasi, membuat isi pelajaran tidak mudah terlupakan, dan membuat proses belajar atau komunikasi berjalan lancar. Sedangkan Menurut Hamalik (1986:43 dalam Ritna 2013) berpendapat bahwa "Gambar adalah segala sesuatu yang diwujudkan secara visual dalam bentuk dua dimensi sebagai curahan perasaan atau pikiran".

Tujuan penelitian: untuk meningkatkan kualitas pembelajaran PKn melalui model make a match berbantuan media kartu bergambar siswa kelas V SDN Karanganyar 02 Kota Semarang.

\section{METODE}

Jenis penelitian yang dilakukan adalah penelitian tindakan kelas. Subjek dalam penelitian ini adalah guru dan siswa kelas V SDN Karanganyar 02 Kota Semarang. Variabel penelitiannya yaitu keterampilan guru, aktivitas siswa, dan hasil belajar siswa dalam pembelajaran PKn melalui model make a match berbantuan media kartu bergambar siswa kelas V SDN Karanganyar 02 Kota Semarang. Penelitian tindakan kelas ini dilaksanakan dalam tiga siklus, setiap siklus satu kali pertemuan dengan empat tahapan yaitu perencanaan, pelaksanaan, observasi, dan refleksi (Arikunto, 2009). Teknik pengumpulan data menggunakan tes dan nontes. Sedangkan teknik analisis data menggunakan teknik analisis deskriptif kuantitatif dan kualitatif. Teknik analisis deskriptif kuantitatif berupa hasil belajar. Teknik analisis deskriptif kualitatif berupa data hasil observasi keterampilan guru dan aktivitas siswa, wawancara dan catatan lapangan. Adapun penyajian teknik analisis data tersebut adalah sebagai berikut:

Data kuantitatif

Menentukan nilai rerata kelas dengan rumus : (Aqib, 2011: 40)

Dengan:

$$
\mathbf{X}=\frac{\sum \mathbf{X}}{\sum \mathbf{N}}
$$

$\mathrm{X}=$ nilai rata-rata

\section{Data Kualitatif}

$$
\begin{array}{ll}
\sum X & =\text { jumlah semua nilai siswa } \\
\sum N & =\text { jumlah siswa }
\end{array}
$$

$$
i=\frac{\text { skor tertinggi-skor terendah }(R)}{\text { jumlah interval kelas }}
$$

Keterangan:

$\mathrm{i}=$ jarak interval

Rumus tersebut digunakan untuk menentukan klasifikasi berdasarkan skor dalam pembuatan kriteria penilaian terhadap keterampilan guru dan aktivitas siswa (Widoyoko,

\begin{tabular}{|c|c|c|c|c|}
\hline \multirow{2}{*}{ No } & \multirow{2}{*}{ Indikator } & \multicolumn{3}{|c|}{ Skor yang diperoleh } \\
\hline & & Siklus I & Siklus II & Siklus III \\
\hline 1. & $\begin{array}{l}\text { Mengkondisikan siswa agar siap dalam } \\
\text { mengikuti pelajaran }\end{array}$ & 2 & 3 & 4 \\
\hline 2. & Memberikan variasi & 3 & 4 & 4 \\
\hline 3. & $\begin{array}{l}\text { Menyampaikan materi dengan bantuan } \\
\text { media kartu bergambar }\end{array}$ & 3 & 3 & 4 \\
\hline 4. & $\begin{array}{l}\text { Memberikan kesempatan siswa untuk } \\
\text { bertanya materi yang belum jelas }\end{array}$ & 1 & 2 & 2 \\
\hline
\end{tabular}
2012:106-110)

\section{HASIL DAN PEMBAHASAN}

Tabel 1. Peningkatan Keterampilan Guru pada Siklus I, Siklus II dan Siklus III 


\begin{tabular}{|c|c|c|c|c|}
\hline 5. & $\begin{array}{l}\text { Mengelola kelas dengan membagi siswa } \\
\text { menjadi } 3 \text { kelompok }\end{array}$ & 4 & 4 & 4 \\
\hline 6. & $\begin{array}{l}\text { Membimbing siswa menemukan kartu } \\
\text { pasangan make a match }\end{array}$ & 2 & 3 & 3 \\
\hline 7. & $\begin{array}{l}\text { Membimbing siswa mempresentasikan kartu } \\
\text { pasangan make a match }\end{array}$ & 4 & 4 & 4 \\
\hline 8. & $\begin{array}{l}\text { Memberikan kesempatan siswa untuk } \\
\text { menanggapi hasil presentasi }\end{array}$ & 3 & 3 & 3 \\
\hline 9. & Memberikan penguatan hasil kerja siswa & 2 & 2 & 3 \\
\hline \multirow[t]{4}{*}{10.} & Menyimpulkan dan menutup pelajaran & 4 & 4 & 4 \\
\hline & \multirow{3}{*}{$\begin{array}{c}\text { Jumlah Skor yang Diperoleh } \\
\text { Persentase } \\
\text { Kategori }\end{array}$} & 28 & 32 & 35 \\
\hline & & $70 \%$ & $80 \%$ & $87,5 \%$ \\
\hline & & Baik & Baik & $\begin{array}{c}\text { Sangat } \\
\text { Baik }\end{array}$ \\
\hline
\end{tabular}

Berdasarkan tabel 1, keterampilan guru pada siklus I, II dan III mengalami peningkatan. Peningkatan keterampilan guru mencakup delapan keterampilan dasar mengajar menurut Wardani (2004: 25-39) diantaranya: 1) Keterampilan membuka dan menutup pelajaran, 2) Keterampilan bertanya, 3) Keterampilan memberikan penguatan, 4) Keterampilan mengadakan variasi, 5) Keterampilan menjelaskan, 6) Keterampilan membimbing diskusi kelompok kecil, 7) Keterampilan mengelola kelas, dan 8) Keterampilan mengajar kelompok kecil dan perorangan

Tabel 2 Peningkatan Aktivitas Siswa pada Siklus I, Siklus II dan Siklus III

\begin{tabular}{|c|c|c|c|c|}
\hline \multirow{2}{*}{ No } & \multirow{2}{*}{ Indikator Aktivitas Siswa } & \multicolumn{3}{|c|}{ Skor yang diperoleh } \\
\hline & & Siklus I & Siklus II & Siklus III \\
\hline 1 & $\begin{array}{l}\text { Mempersiapkan diri } \text { dalam } \\
\text { pembelajaran }\end{array}$ & 84 & 85 & 103 \\
\hline 2 & $\begin{array}{l}\text { Memperhatikan tampilan media kartu } \\
\text { bergambar }\end{array}$ & 103 & 109 & 117 \\
\hline 3 & Mendengarkan penjelasan dari guru & 90 & 95 & 103 \\
\hline 4 & Mengajukan dan menjawab pertanyaan & 50 & 56 & 69 \\
\hline 5 & Membentuk kelompok sesuai pembagian & 115 & 118 & 129 \\
\hline 6 & $\begin{array}{l}\text { Melaksanakan kegiatan belajar dan kerjasama } \\
\text { secara berkelompok dengan model } \\
\text { pembelajaran make a match. }\end{array}$ & 106 & 110 & 122 \\
\hline 7 & $\begin{array}{l}\text { Mempresentasikan pasangan kartu make a } \\
\text { match }\end{array}$ & 57 & 74 & 89 \\
\hline 8 & Menanggapi hasil diskusi & 59 & 73 & 79 \\
\hline 9 & $\begin{array}{l}\text { Melakukan } \quad \text { refleksi } \quad \text { terhadap } \\
\text { pembelajaran }\end{array}$ & 83 & 103 & 113 \\
\hline 10 & $\begin{array}{c}\text { Mengerjakan soal evalusi } \\
\text { Jumlah skor total yang diperoleh } \\
\text { Jumlah Rata-rata skor total } \\
\text { Persentase }\end{array}$ & $\begin{array}{c}122 \\
869 \\
21,7 \\
54,31 \%\end{array}$ & $\begin{array}{c}128 \\
951 \\
25,03 \\
62,57 \%\end{array}$ & $\begin{array}{c}141 \\
1065 \\
28,03 \\
70,07 \%\end{array}$ \\
\hline & Kategori & Cukup & Baik & Baik \\
\hline
\end{tabular}

Berdasarkan tabel 2, menunjukkan aktivitas siswa pada siklus I, II dan III mengalami peningkatan. Indikator dalam pembelajaran PKn melalui model make a match berbatuan media kartu bergambar sesuai dengan aktivitas siswa menurut Paul B. 
Dierich (dalam Hamalik, 2013) yaitu: (a) Aktivitas visual. (b) Aktivitas lisan (ora). (c) Aktivitas mendengarkan. (d) Aktivitas menulis. (e) Aktivitas menggambar. (f) Aktivitas motorik. (g) Aktivitas mental. (h) Aktivitas emosional

\begin{tabular}{|c|c|c|c|c|}
\hline \multirow[t]{2}{*}{ No } & \multirow[t]{2}{*}{ Pencapaian } & \multicolumn{3}{|c|}{ Skor yang diperoleh } \\
\hline & & Siklus I & Siklus II & Siklus III \\
\hline 1 & Nilai tertinggi & 86 & 94 & 96 \\
\hline 2 & Nilai terendah & 50 & 50 & 52 \\
\hline 3 & Siswa tuntas & 25 & 29 & 33 \\
\hline 4 & Siswa tidak tuntas & 15 & 9 & 5 \\
\hline 5 & Persentase Ketuntasan Klasikal & $63 \%$ & $76,32 \%$ & $86,84 \%$ \\
\hline 6 & Nilai Rata-rata & 67,47 & 72,26 & 76,53 \\
\hline
\end{tabular}

Berdasarkan tabel 3, terlihat adanya peningkatan hasil belajar siswa dalam pembelajaran PKn melalui model make a match berbantuan media kartu bergambar. Dari tabel tersebut dapat diketahui bahwa nilai rata-rata yang awalnya hanya 67,47 pada siklus I, kemudian meningkat menjadi 72,26 pada siklus II, dan meningkat menjadi 76,53 pada siklus III. Perolehan nilai setiap siswa, pada siklus I nilai tertinggi 86 , kemudian meningkat menjadi 94 pada siklus II meningkat menjadi 96 pada siklus III. Sama halnya dengan perolehan nilai tertinggi, perolehan nilai terendah pun mengalami peningkatan dari 50 pada siklus I dan II meningkat menjadi 52 pada siklus III. Selain itu, peningkatan terjadi pada jumlah siswa yang tuntas pada mata pelajaran PKn, yaitu ada 25 siswa pada siklus I, meningkat menjadi 29 siswa pada siklus II dan meningkat lagi menjadi 33 siswa pada siklus III. Oleh sebab itu jumlah siswa yang tidak tuntas pun mengalami penurunan pada setiap siklus. Ada 15 siswa yang tidak tuntas pada siklus I, kemudian menurun menjadi 9 siswa pada siklus II dan akhirnya hanya 5 siswa yang tidak tuntas pada siklus III. Hal tersebut menunjukan bahwa adanya peningkatan pada ketuntasan belajar siswa secara klasikal. Bisa dilihat dari persentase pencapaian ketuntasan klasikal yaitu sebesar $63 \%$ pada siklus I, kemudian meningkat menjadi $76,32 \%$ pada siklus II dan mencapai $86,84 \%$ pada siklus III.

\section{SIMPULAN}

Berdasarkan hasil penelitian dan pembahasan mengenai kualitas pembelajaran PKn melalui model make a match berbantuan media kartu bergambar siswa kelas $\mathrm{V}$ SDN Karanganyar 02 Kota Semarang dapat disimpulkan keterampilan guru meningkat setiap siklus, pada siklus I memperoleh skor 28 dengan kriteria baik, siklus II memperoleh skor 32 dengan kriteria baik dan siklus III memperoleh skor 35 dengan kriteria sangat baik, aktivitas siswa meningkat setiap siklus, siklus I memperoleh ratarata skor 21,7 dengan kriteria cukup, siklus II memperoleh skor 25,03 dengan kriteria baik dan siklus III memperoleh skor 28, 03 dengan kriteria baik, hasil belajar siswa meningkat tiap siklus, dengan ketuntasan klasikal siklus I 63\%, siklus II 76,32 \%, dan siklus III $86,84 \%$.

\section{DAFTAR PUSTAKA}

Aqib, Z, Dkk. 2011. Penelitian Tindakan Kelas Untuk Guru SD,SLB, TK. Bandung: CV. Yrama Widya

Arikunto, Suharsimi, Dkk. 2008. PENELITIAN TINDAKAN KELAS. Jakarta: PT Bumi Aksara. 
BNSP. 2006. Panduan Penyusunan Kuriklum Tingkat Satuan Pendidikan Jenjang Pendidikan Dasar Dan Menengah. Jakarta: Depdiknas.

Hamalik, O. 2013. PROSES BELAJAR MENGAJAR. Jakarta: PT Bumi Aksara.

Huda, M. 2011. MODEL-MODEL PENGAJARAN DAN PEMBELAJARAN. Yogyakarta: Pustaka Pelajar.

Muslimah, E, 2012. Peningkatan Hasil Belajar Pkn Materi Bangga Sebagai Bangsa Indonesia Melalui Pembelajaran Kooperatif Tipe Make A Match Siswa Kelas III SD Negeri Kemandungan 3 Kota Tegal. Skripsi, Pendidikan Guru Sekolah Dasar, Fakultas IImu Pendidikan Universitas Negeri Semarang

Poerwanti.E, Dkk. 2008. Asesmen Pembelajaran SD. Jakarta: Direktorat Jendral Pendidikan Tinggi Departemen Pendidikan Nasional.

Ritna. 2013. Meningkatkan Hasil Belajar Siswa Kelas IV Dalam Pembelajaran IPS Dengan Menggunakan Media Gambar Di SD Inpres III Tada. Fakultas Keguruan Dan Ilmu Pendidikan, Universitas Tadulako. Jurnal Nasional Vol. 1 No. 1.

(Http://Jurnal.Untad.Ac.Id/Jurnal/Index.Php/JKTO/Article/View/2511/1655

Diunduh Senin, 13 April 2015 Pukul 20.00)

Suharti. 2009. Media Kartu Bergambar Untuk Meningkatkan Prestasi Belajar Pendidikan Kewarganegaraan Anak Tunagrahita Sedang Pada Kelas C1 Sdlb Negeri Purworejo Tahun Pelajaran 2008/2009. Skripsi, Program Studi Pendidikan Luar Biasa, Fakultas Keguruan Dan IImu Pendidikan, Universitas Sebelas Maret Surakarta.

Wardani. 2004. Pemantapan Kemampuan Mengajar. Jakarta: Universitas Terbuka.

Widoyoko, E. 2012. Teknik Penyusunan Instrumen Penelitian. Yogyakarta: Pustaka Pelajar. 